ARTICLE

Received 30 Mar 2013 | Accepted 2 Jul 2013 | Published 16 Aug $2013 \quad$ DOl: 10.1038/ncomms3217

\title{
Mutation in the seed storage protein kafirin creates a high-value food trait in sorghum
}

Yongrui Wuㄴ, Lingling Yuan², Xiaomei Guo ${ }^{2}$, David R. Holding ${ }^{2} \&$ Joachim Messing ${ }^{1}$

Sustainable food production for the earth's fast-growing population is a major challenge for breeding new high-yielding crops, but enhancing the nutritional quality of staple crops can potentially offset limitations associated with yield increases. Sorghum has immense value as a staple food item for humans in Africa, but it is poorly digested. Although a mutant exhibiting high-protein digestibility and lysine content has market potential, the molecular nature of the mutation is previously unknown. Here, building on knowledge from maize mutants, we take a direct approach and find that the high-digestible sorghum phenotype is tightly linked to a single-point mutation, rendering the signal peptide of a seed storage protein kafirin resistant to processing, indirectly reducing lysine-poor kafirins and thereby increasing lysine-rich proteins in the seeds. These findings indicate that a molecular marker can be used to accelerate introduction of this high nutrition and digestibility trait into different sorghum varieties.

\footnotetext{
${ }^{1}$ Waksman Institute of Microbiology, Rutgers University, 190 Frelinghuysen Road, Piscataway, New Jersey 08854, USA. ${ }^{2}$ Department of Agronomy and Horticulture, Center for Plant Science Innovation, University of Nebraska, Lincoln, E323 Beadle Center for Biotechnology, 1901 Vine Street, PO Box 880660 , Lincoln, Nebraska 68588-0665, USA. Correspondence and requests for materials should be addressed to J.M. (email: messing@waksman.rutgers.edu).
} 
S orghum (Sorghum bicolor (L.) Moench) is a droughttolerant C4 crop, one-third of which $(\sim 20$ million tonnes of grain) is produced in the African continent from where it originates. Much of Africa has semi-arid, tropical or sub-tropical climate conditions in which maize cannot be grown because of water scarcity. Thus, its close relative, sorghum, has become the only viable food grain for many of the world's most food-insecure people. Sorghum is also used as feed for animals in both developed and developing countries. One advantage of growing sorghum is that it usually does not compete for the lands, where other crops such as maize, wheat and rice can be grown.

However, like other cereals, sorghum has poor protein quality because of lack of essential amino acids such as lysine and tryptophan ${ }^{1-4}$. Compounding this problem, sorghum proteins have very poor digestibility. These properties result in severe malnutrition when sorghum is consumed as the primary protein source $^{3}$. The predominant seed proteins in sorghum are alcoholsoluble prolamins called kafirins. Kafirins comprise $>70 \%$ of the total seed protein and serve as a repository of reduced nitrogen for breakdown and recycling into the proteins of the germinating seedling. Based on their molecular weight and sequence, they are classified into four classes, namely, $\alpha, \beta, \gamma$ and $\delta^{5,6}$. Similar to the maize zeins, kafirins are stored in the endoplasmic reticulum (ER) in spherical protein bodies (PBs), in which $\beta$ - and $\gamma$-kafirins are located in the peripheral PB region and $\alpha$ - and $\delta$-kafirins are encapsulated in the inner region ${ }^{7,8}$. The $\alpha$-kafirins are the last proteins to be digested in the intestine and, because of their high abundance, the indigestibility reduces their nutritive value. The $\beta$ - and $\gamma$-kafirins are rich in cysteine, which form disulphide bonds and are therefore assumed to block the accessibility of $\alpha$-kafirins to hydrolytic enzymes ${ }^{9-12}$. A dominant floury mutant P721Q induced by chemical mutagenesis that exhibits significantly higher protein digestibility ${ }^{13}$ has been shown to have market potential $^{14}$. Furthermore, this mutant has a higher lysine content than the normal sorghum isoline, $\mathrm{P} 721 \mathrm{~N}^{15}$. The enhanced lysine level results mainly from an increase in lysine-rich non-kafirins, which further results from a slight decrease in lysine-deficient kafirins ${ }^{14}$. Like the $o 2$ mutant in maize, this mutant has soft seed texture and is more susceptible to grain moulds. The $o 2$ variant has been commercialized by selecting quantitative trait loci (QTLs) to overcome its inferior traits, resulting in the quality protein maize ${ }^{16,17}$. Correspondingly, a modified version of hdhl with harder endosperm has also been developed ${ }^{18}$. In the developing mutant endosperm, the PBs had irregular, invaginated shapes. It was hypothesized that the invagination of PBs resulted in expansion of their surface area to proteolytic enzymes, thereby increasing protein digestibility ${ }^{12}$.

We sought to characterize the molecular basis of lysine and digestibility improvements to provide molecular markers for accelerated introgression into sorghum cultivars. Analogous to the sorghum phenotype, similar irregular and clumped PB morphologies in endosperm cells have previously been observed in two maize mutants with semi-dominant and dominant floury kernels ${ }^{19-21}$. These mutants resulted from point mutations at different sites in the ER signal peptides of a $22-\mathrm{kDa} \alpha$-zein (floury 2$)$ and a $19-\mathrm{kDa} \alpha$-zein $\left(D e^{*}{ }^{*} B 30\right)$. These mutations resulted in incorrectly processed mature zeins that remained tethered to the ER membrane $e^{21-23}$. Because of the phenotypic similarity, we hypothesized that the P721Q mutation in sorghum could be an aberrant kafirin.

We used a pair of polymorphic SSR markers to follow the known locus of $22-\mathrm{kDa} \alpha$-kafirin genes that we have cloned and characterized previously ${ }^{24}$. Indeed, we found that the polymorphic allele from P721Q was tightly linked to the floury phenotype in the $\mathrm{F} 1$ and $\mathrm{BC} 1$ populations. Because kafirin genes are the result of recent tandem amplification in the genome and are thus highly similar, we used random genomic and complementary DNA (cDNA) sequencing of $22-\mathrm{kDa} \alpha$-kafirin genes and mRNAs in P721Q. Indeed, we identified a single mutant-specific kafirin gene copy that had a missense mutation in the signal peptide. To confirm that such a mutation renders the protein resistant to processing, we compared normal and mutant kafirin expression in transgenic maize. The mutant kafirin not only remained unprocessed in maize, but also triggered the unfolded protein response (UPR) and the formation of irregular PBs as observed in sorghum P721Q endosperm. Therefore, these results validate our direct approach to explain the mechanism of a valuable trait in agriculture and offer a molecular marker for introgressing such a trait into local germplasm, thereby increasing the acreage of more nutritious food.

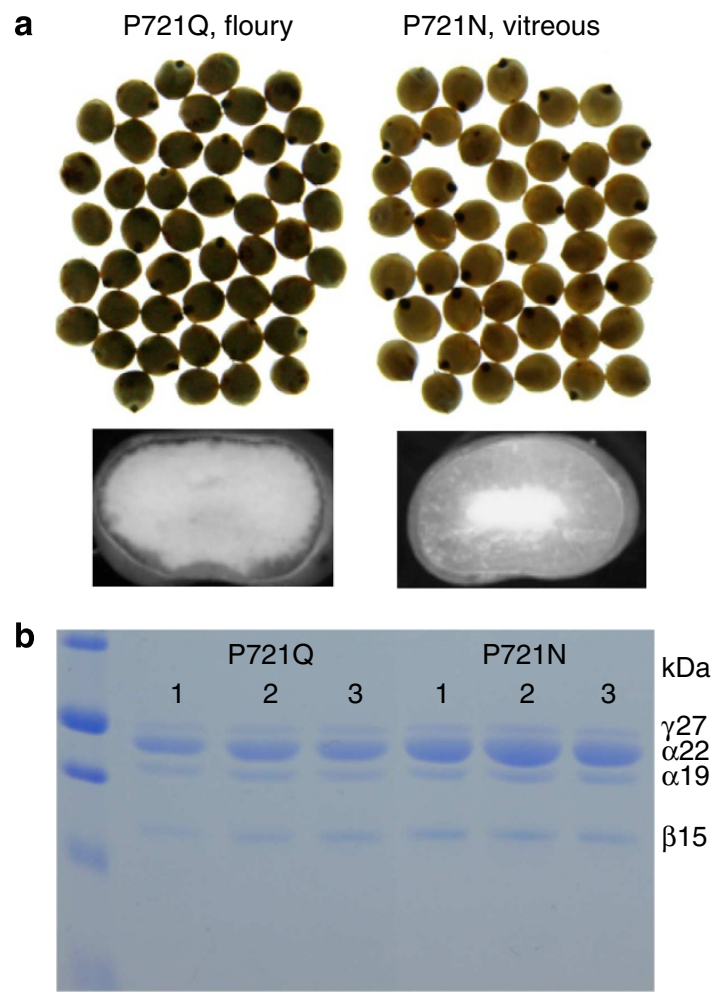

Figure 1 | Characterization of the phenotype of the highly digestible highlysine mutant. (a) Seed phenotype of P721Q and P721N. (b) Kafirin accumulation patterns of P721Q and P721N analysed by SDS-PAGE. Protein markers in the leftmost lane from top to bottom are 37, 25, 20, 15 and $10 \mathrm{kDa}$. Total kafirin loaded in each lane was equal to $200 \mu \mathrm{g}$ of sorghum flour. The size for each band is indicated.

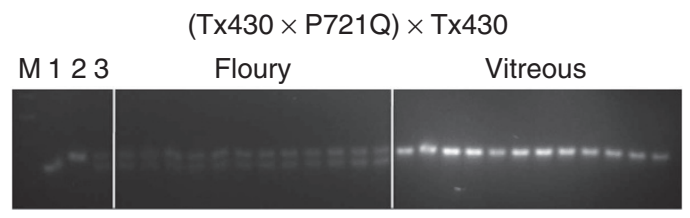

Figure 2 | Linkage analysis of the floury phenotype with a SSR marker from Chr. 5 near to the 22-kDa $\alpha$-kafirin cluster. The floury progeny seeds all contained the lower band originated from $\mathrm{p} 721 \mathrm{Q}$, whereas the vitreous progeny uniformly yielded the single band from Tx430. M: DNA markers from top to bottom are 400, 300, 200 and 100 bp; lane 1, P721Q; lane 2, Tx430; lane 3, F1 of Tx430 × P721Q. 


\section{Results}

Genetic analysis of the mutant phenotype hdhl. The highly digestible high-lysine ( $h d h l$ ) mutant P721Q (Q for opaque) was generated by chemical mutagenesis (diethyl sulphate treatment) from P721N ( $\mathrm{N}$ for normal) and exhibited kernels with a floury, non-vitreous phenotype ${ }^{15}$ (Fig. 1a). The reduced accumulation of the main storage protein kafirins (Fig. 1b) in P721Q raised its lysine to a higher level than that of P721N ${ }^{25}$. To map $h d h l, \mathrm{P} 721 \mathrm{Q}$ was crossed with $\mathrm{Tx} 430$ in reciprocal directions and all F1 seeds were floury, indicating that the action of $h d h l$ is completely dominant. F1 seeds were subsequently self-pollinated or backcrossed to $\mathrm{Tx} 430$ as female, which gave rise to 3:1 segregation of floury and vitreous seeds in $\mathrm{F} 2$ and $1: 1$ in $\mathrm{BC} 1$, indicating that $h d h l$ is a single locus. If the phenotype is caused by a mutation in the signal peptide of a kafirin gene, we could determine whether it is linked to these genes and whether one of its copies has such a specific mutation. We previously determined by comparative genomics that all $20 \alpha$-kafirin genes were clustered on Chr. 5 of the BTx623 genome ${ }^{26}$. SSR markers were designed based on the BAC SB40L16 sequence, which comprises a cluster of 10 active $22-\mathrm{kDa} \alpha$-kafirin genes of Btx623 within $35 \mathrm{~kb}$, a sorghum

\begin{tabular}{|c|c|c|c|c|}
\hline \multirow{2}{*}{$\frac{\text { Population }}{\mathrm{BC} 1(f l: v t=1: 1)}$} & \multicolumn{2}{|c|}{ No. of seeds for genotyping } & \multicolumn{2}{|c|}{ Genotypes ${ }^{\dagger}$} \\
\hline & BC1-floury & 44 & $\begin{array}{c}\mathrm{Q} / \mathrm{T} \\
\mathrm{T}\end{array}$ & $\begin{array}{c}44 \\
0\end{array}$ \\
\hline & $\mathrm{BC1}$-vitreous & 44 & $\begin{array}{c}\mathrm{Q} / \mathrm{T} \\
\mathrm{T}\end{array}$ & $\begin{array}{c}0 \\
44\end{array}$ \\
\hline \multirow[t]{2}{*}{$\mathrm{F} 2(f l: v t=3: 1)$} & F2-floury & 25 & $\begin{array}{c}\mathrm{Q} \\
\mathrm{Q} / \mathrm{T} \\
\mathrm{T}\end{array}$ & $\begin{array}{c}8 \\
17 \\
0\end{array}$ \\
\hline & F2-vitreous & 25 & $\begin{array}{c}\mathrm{Q} \\
\mathrm{Q} / \mathrm{T} \\
\mathrm{T}\end{array}$ & $\begin{array}{c}0 \\
0 \\
25\end{array}$ \\
\hline
\end{tabular}

Abbreviations: fl, floury; vt, vitreous.

${ }^{\dagger} \mathrm{Q}$, the polymorphic allele from P721Q; T, the polymorphic allele from Tx430. chromosome segment that, as a whole, became integrated in the maize genome by transformation ${ }^{27}$. Transgenic maize seeds expressed and processed kafirins properly and served as a positive control in our experiments below.

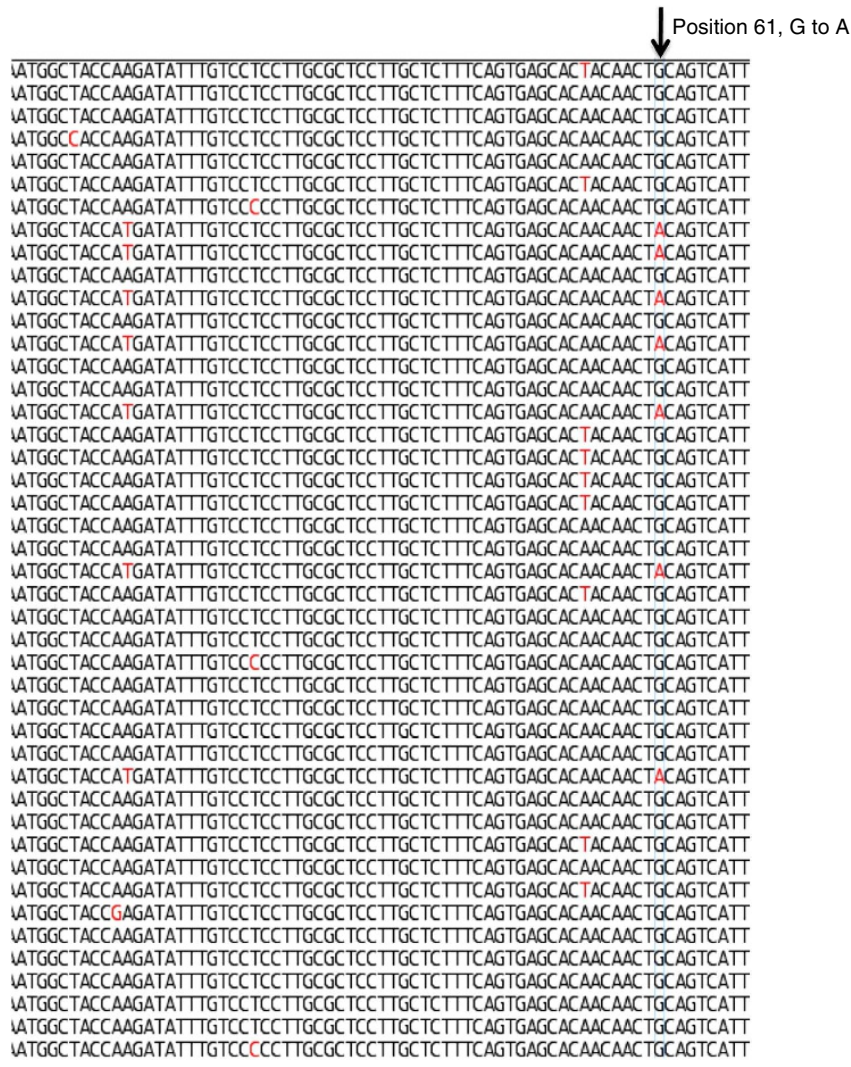

Figure 3 | Partial alignment of the 22-kDa $\alpha$-kafirin cluster amplified from P721Q genomic DNA. The position of the $G \rightarrow A$ substitution is marked with the downward arrow. a

$k 1 C 16$

$k 1 C 17$

$k 1 C 01$

$k 1 C 12$

$k 1 C 10$

$k 1 C 11$

k1C09

k1C08

k1C07

k1C06

k1C05

k1C04

$\mathrm{k} 1 \mathrm{CO} 3$

k1CO2

k1C14

k1C13

$k 1 C 18$

$k 1 C 20$

k1C19

k1A01

k1A02

721Q-HD

\begin{tabular}{|c|c|}
\hline \multicolumn{2}{|l|}{$\begin{array}{c}21 \\
\downarrow\end{array}$} \\
\hline & \\
\hline & \\
\hline & \\
\hline SVSATTAVIIP & \\
\hline & \\
\hline & \\
\hline & \\
\hline IIP & \\
\hline IIP & \\
\hline IIP & \\
\hline IIP & \\
\hline IP & \\
\hline & \\
\hline IIP & \\
\hline TTAVIIP & \\
\hline & \\
\hline IP & \\
\hline & \\
\hline & \\
\hline MAAKLFS & \\
\hline AAKIFSLVMLLALFAS & \\
\hline 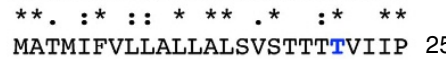 & \\
\hline
\end{tabular}

b

azs 22.16

azs 22.8

azs 22.9

azs 22.4

azs 22.7

azs 22.12

$z 1 A 1$

$z 1 A 2$

$z 1 D 1$

Z1B2

Z1D2

$z 1 B 1$

f12
21

MATKILALLALLALLVSATNAFIIP 25 MATKILALLALLALFVSATNAFIIP 25 MATKILALLALLALFVSATNAFIIP 25 MATKILSLLALLALFASATNAFIIP 25 MASKTLSLLALLALFVSATNAFIIP 25 MATKILALLALLSLSVSATTAFIIP 25 MAAKIFCFLMLLGLSASAATATIFP 25 MAAKIFCFLMLLGLSASVATATIFP 25 MAAKIFAILALLALSASVATATIIP 25 MATKIFSLLMLLALSTCVANATIFP 25 MATKIFSLLMLLALSTCVANATIFP 25 MATKIFSLLMLLALSACVANATIFP 25 MATKILALLALLALLVSATNVFIIP 25 GCG (Ala) to GTG (Val)

Figure 4 | Missense mutation at the 21st amino acid of the signal peptide in P721Q-hdhl and maize floury2 mutants. The missense mutation is marked with an arrow at the 21st amino acid of the signal peptide in P721Q-hdhl (a) and maize floury2 (b). (a) P721Q-hdhl harbouring the G $\rightarrow$ A transition resulted in Ala being replaced with Thr; (b) maize floury2 containing $\mathrm{C} \rightarrow \mathrm{T}$ transition caused the replacement of Ala with Val. 
Although there were other $22-\mathrm{kDa} \alpha$-kafirin genes within a million base pairs on the same chromosome ${ }^{26}$, the selected SSR markers showed that the tandem kafirin cluster on BAC SB40L16 was tightly linked to seed floury and vitreous phenotypes and the recombination frequency was $<1 \%$ (Fig. 2 and Table 1 ). We used universal primers based on the conserved $5^{\prime}$-UTR and $3^{\prime}$-end of the coding sequence (CDS) regions of the $22-\mathrm{kDa} \alpha$-kafirin gene cluster to amplify, from genomic DNA, all copies from P721N and P721Q for sequencing with ABI-3730 capillary electrophoresis. We found that seven out of 77 sequences had a single nucleotide $G \rightarrow A$ substitution at position 61 relative to the first nucleotide of the start codon (Fig. 3), whereas no such mutation was found in 96 sequences from P721N. Because we previously had already indicated that all 10 kafirin genes in the cluster are expressed ${ }^{27}$, these results would be consistent with one out of 10 gene copies of the kafirin cluster producing the mutant protein. We also analysed cDNA sequences of the $22-\mathrm{kDa} \alpha-$ kafirin genes from their developing endosperms and confirmed

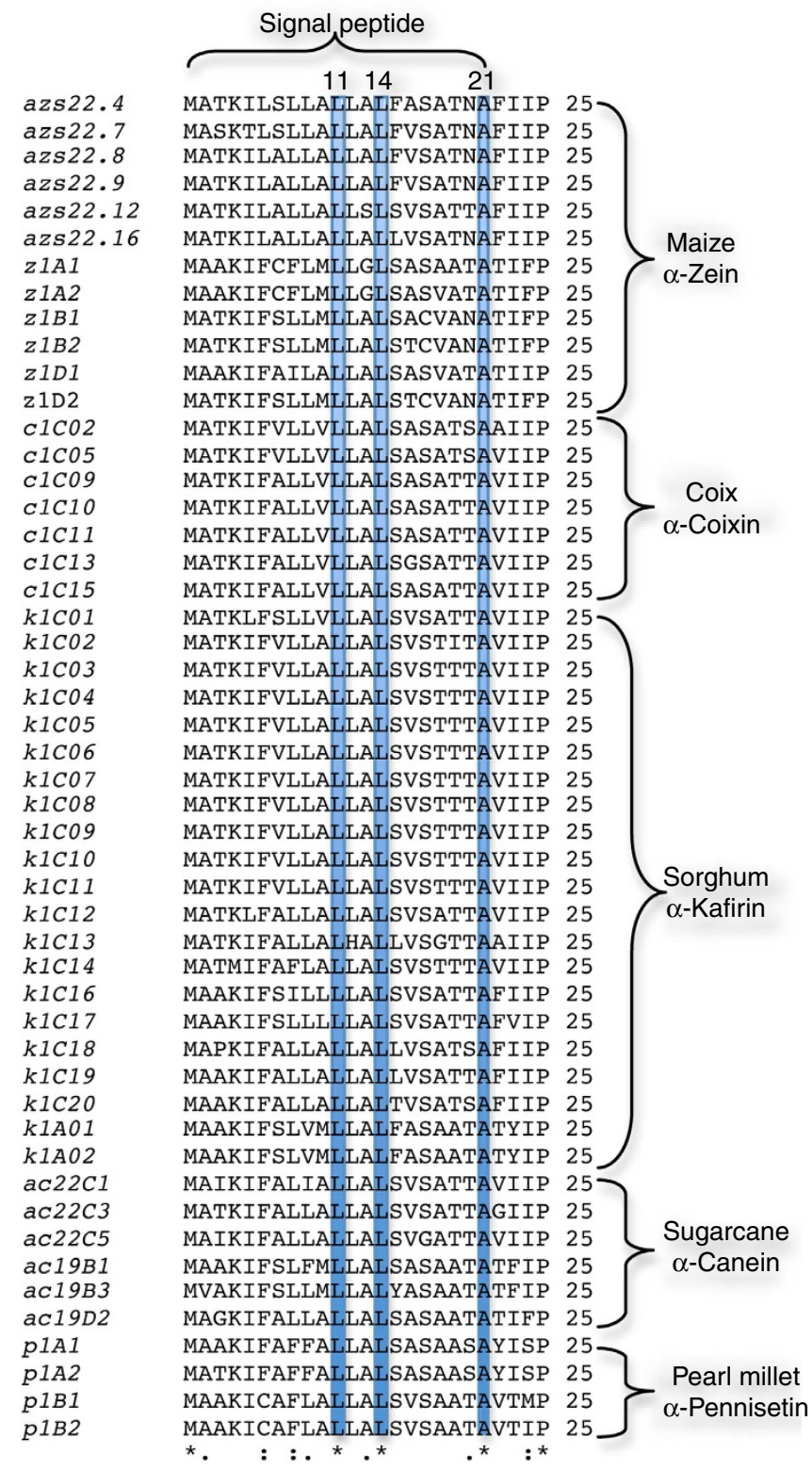

Figure 5 | Alignment of the signal peptides of $\alpha$-prolamins from the grass subfamily. Three amino acids at positions 11,14 and 21 are highly conserved except for the start codon. that the mutant transcript was only present in P721Q (five out of 96). This missense mutation results in the last amino acid alanine (Ala) in the signal peptide being replaced with threonine (Thr) (Fig. 4).

Conservation of $\alpha$-prolamin signal peptides in Panicoideae. The $\alpha$-kafirins and $\alpha$-zeins arose late in the evolution of the prolamins and have been found in the subfamily of the Panicoideae that include the sequenced genomes of foxtail millet, sorghum and maize ${ }^{24}$. Their signal peptide is 21 amino acids long and is cleaved when the protein is transported into the inner side of PB for storage. The Ala at position 21 is critical for cleavage, as it is conserved in all 19 - and $22-\mathrm{kDa} \alpha$-prolamins in foxtail millet, sorghum, coix and maize (Fig. 5). In the floury 2 mutant of maize, the same Ala is replaced with valine (Val) in a $22-\mathrm{kDa}$ alpha zein (Fig. 4), resulting in the retention of the signal peptide at maturity. As a consequence, the immature zein is tethered to the PB membrane, resulting in irregular PBs. When signal peptides from $\alpha$-prolamins of species of the Panicoideae such as maize, coix, sorghum, sugarcane and pearl millet were aligned, only three amino acids were completely conserved except for the start codon, leucine at positions 11 and 14 and Ala at 21 (Fig. 5).

Phenocopying of irregular PBs in maize with kafirin mutant. To demonstrate that this mutation indeed renders the kafirin resistant to signal peptide processing, we took advantage of the transgenic maize line as a control, in which we expressed the normal kafirin cluster ${ }^{27}$. We wanted to use a heterologous system to exclude any other sorghum protein and sequence in this test. Using only the mutant sorghum transcript under the control of the maize $22-\mathrm{kDa} \alpha$-zein promoter, we transformed maize with the mutant gene construct. The construct was also coupled with the visible GFP marker driven by the $10-\mathrm{kDa} \delta$-zein promoter to facilitate scoring of positive progeny seeds (Fig. 6a). At 18 days after pollination (DAP), a number of immature kernels were collected and these segregated 1:1 for green and non-green seeds. The null segregant and positive transgenic endosperms were used to extract RNA. Reverse transcription (RT)-PCR analysis confirmed that the green seeds highly expressed the mutant sorghum allele (Fig. 6b). Furthermore, western blot analysis with a $22-\mathrm{kDa} \alpha$-zein antibody showed that in transgenic maize harbouring the mutant kafirin gene, a slower migrating protein band $(24 \mathrm{kDa})$ above the processed $22-\mathrm{kDa} \alpha$-zein is visible. This band is absent in the control with the normal kafirin genes in separate transgenic maize lines (Fig. 6c). Moreover, a transacting gain of function was observed. Expression of the Bip gene was significantly enhanced, indicating that the unprocessed kafirin induces the UPR in maize (Fig. 6d). As a consequence, the levels of the $22-\mathrm{kDa} \alpha$-zeins were noticeably reduced compared with the null segregants (Fig. 6c), consistent with the observation in P721Q (Fig. 1b) and the UPR-induced translational repression.

The level of the mutant kafirin in comparison with the total $\alpha$-zein is relatively low, but it was previously shown that the dominant-negative 19 -kDa $\alpha$-zein in the $D e-{ }^{\star} B 30$ mutant induces dramatic $\mathrm{PB}$ alterations and UPR with very low levels of accumulation $^{21}$. Nevertheless, we wondered whether the mutant protein is sufficient to trigger a deformation of $\mathrm{PBs}$ as it has been observed in P721Q. Therefore, transmission electron microscopy (TEM) examination was also performed with endosperms of maize from transgenic and non-transgenic lines. Indeed, this low level of the mutant kafirin gave rise to PBs that were all irregular and frequently clumped, whereas the $\mathrm{PBs}$ of maize transformed with non-mutant kafirins and the null-segregant control showed normal phenotype (Figs 6e and 7). Therefore, we showed that the 
a

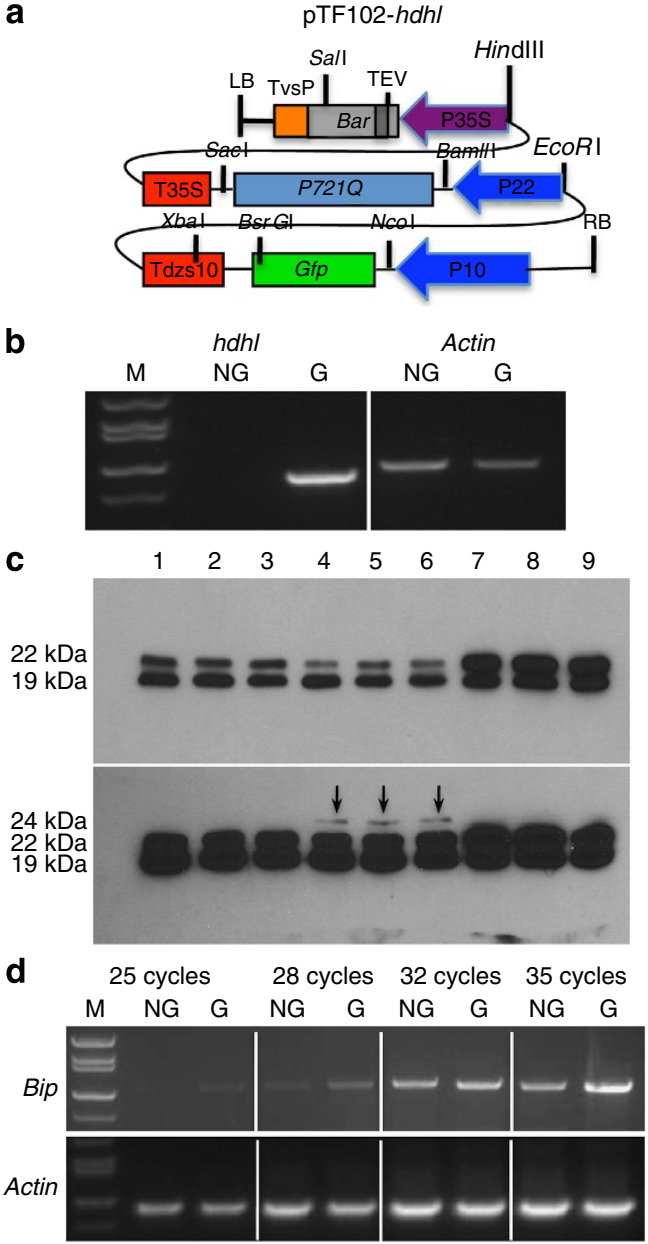

e

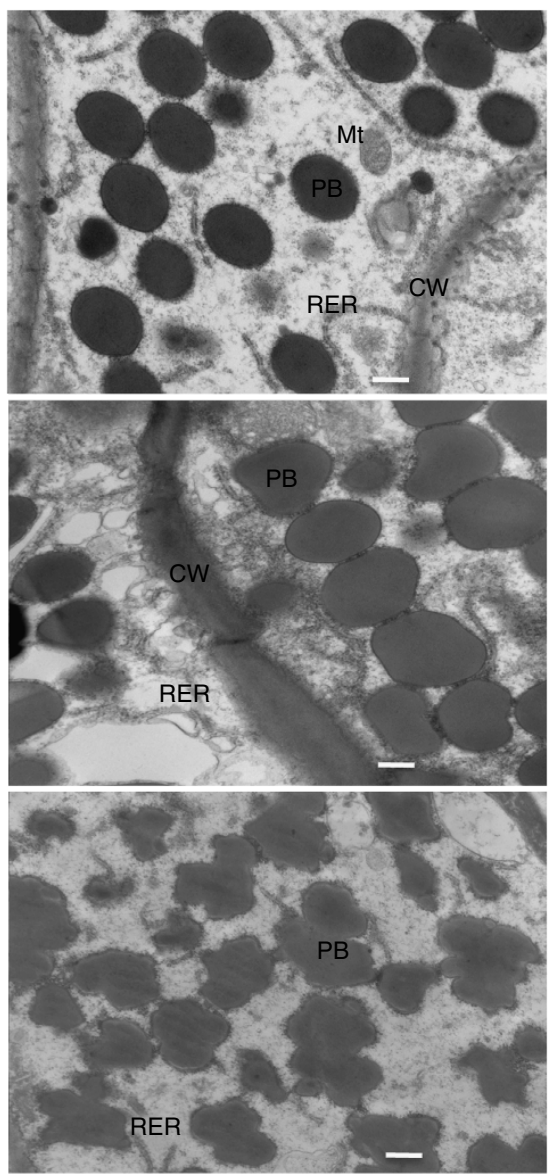

Figure 6 | Expression of mutant and normal kafirin genes in maize. (a) pTF102-mutant kafirin construct. (b) RT-PCR analysis of the expression of mutant kafirin in maize endosperm at 18 DAP. NG, non-green (null segregant); G, green (mutant kafirin); M, DNA markers from top to bottom are 2, 1.5, 1.4, 1 and $0.75 \mathrm{~kb}$. (c) Western blot analysis of kafirin accumulation. Highly diluted protein loaded in each lane represents prolamins extracted from $0.5 \mu \mathrm{g}$ maize flour. The antiserum can crossreact with the 22-kDa $\alpha$-zeins/kafirins and 19-kDa $\alpha$-zeins. The unprocessed mutant $22-\mathrm{kDa} \alpha-\mathrm{kafirin}(24 \mathrm{kDa}$ ) migrated slower than the 22-kDa $\alpha$-zeins and normal $22-\mathrm{kDa} \alpha$-kafirins, as indicated by arrows. Upper panel, the film exposed for $10 \mathrm{~s}$; bottom panel, the film exposed for $75 \mathrm{~s}$. Lanes 1-3, null segregants without GFP expression; lanes 4-6, mutant kafirin transgenic seeds with GFP expression; lanes 7-9, transgenic seeds expressing normal 22-kDa $\alpha$-kafirins. (d) RT-PCR analysis of the expression of the Bip gene. M, DNA markers from top to bottom are 2 , 1.5, 1.4, 1 and $0.75 \mathrm{~kb}$. The actin gene served as a control. (e) Transmission electron micrographs of PBs in null segregant (upper panel), maize transformed with normal kafirins (middle panel) and mutant kafirin (bottom panel) endosperms at 18 DAP. CW, cell wall; RER, rough endoplasmic reticulum; Mt, mitochondria. Scale bar, $500 \mathrm{~nm}$.

coding region of the mutant gene, which is tightly linked to the $\mathrm{PB}$ phenotype in sorghum $\mathrm{P} 721 \mathrm{Q}$, produces the same phenotype in maize as a gain of function. This also confirmed that as in floury 2 in maize ${ }^{20}$, the compartmentalization of storage proteins in PBs is conserved between the two species.

\section{Discussion}

We have taken a direct approach to investigate a valuable trait in agriculture. A cereal such as sorghum can substitute for maize in areas with low water supply and serve those geographical areas with food. Sorghum also has high nitrogen utilization efficiency, thereby cutting expenses in fertilizer ${ }^{28}$. However, if seed proteins lack digestibility and certain essential amino acids, it would have to be supplemented by other crops that lack drought resistance and require energy-costly nitrogen, such as soya beans. Instead of supplementation, a stand-alone diet with sorghum would be desirable. Therefore, a lysine-enhanced and highly digestible sorghum variety has gained broad attention. Nevertheless, similar to quality protein maize, $h d h l$ requires additional selection to identify modifier genes that make the mutant kernels harder ${ }^{29}$. As shown in maize, the introduction of such different mutations into local germplasm is a complex and time-consuming process ${ }^{30}$.

Unlike P721Q and floury2, the seed phenotype of the transgenic maize expressing the mutant kafirin is vitreous. This difference between $h d h l$ sorghum and transgenic maize shows that disruption of PB structure and induction of UPR per se do not necessarily induce endosperm opacity. On the contrary, residual levels of zeins are apparently high enough to produce normal endosperm texture. The same observation was made when RNA interference was used to reduce $\alpha$-zeins in two types of maize. It was shown that non-vitreous phenotypes could be overcome with a certain threshold of residual $\alpha$-prolamin synthesis. In normal maize, reduction of $\alpha$-zeins gave rise to nonvitreous, high-lysine kernels, but in Illinois High Protein reduction of $\alpha$-zeins with RNA interference left enough $\alpha$-zeins to give rise to vitreous high-lysine kernels ${ }^{31}$.

Given the variability of the phenotype and with the introduction of modifiers for kernel hardness, breeders cannot rely on 

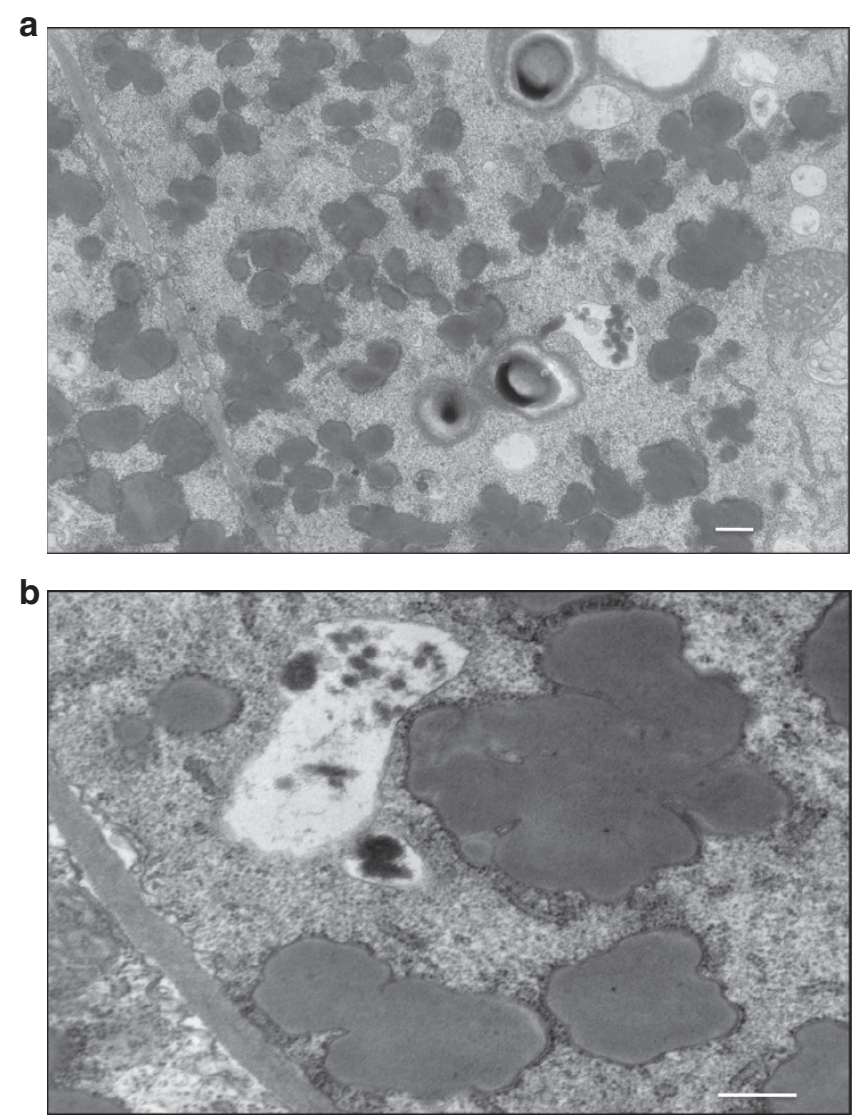

Figure 7 | Transmission electron micrographs of PBs in maize endosperm transformed with mutant kafirin at 18 DAP. (a) View at low magnification. (b) View at higher magnification. Scale bar, $500 \mathrm{~nm}$.

phenotype for the introgression of combined traits into local germplasms. Using a single molecular marker to follow the point mutation in the signal peptide of the mutant kafirin will allow breeders to select their material without relying on a phenotype.

\section{Methods}

Plant materials. Gebisa Ejeta and Bruce Hamaker at Purdue University generously provided sorghum normal and $h d h l$ seeds P721N and P721Q. P721Q was crossed to Tx430, resulting in an F1; then F1 progeny were self-pollinated and backcrossed to Tx430 as female. Maize Hi-II B and A lines for transformation and the transgenic lines expressing normal kafirins were our own materials.

Genetic analysis. The SSR marker (SSR-F: 5'-AGTCAACAACTCCCTCCACC-3'; SSR-R: $5^{\prime}$-ATCGGCTGGTCGTCGACTGAG- ${ }^{\prime}$ ) for segregation analysis was designed near the first 22-kDa $\alpha$-kafirin gene in the BAC SB40L16. In total, 44 samples for each floury and vitreous seed from BC1 and 25 for each from F2 were extracted for genotyping genomic DNA.

Genomic and cDNA sequencing of the 22-kDa $\alpha$-kafirin genes. A universal primer pair priming in the $5^{\prime}$-UTR and at the $3^{\prime}$-end of coding region of the 22-kDa $\alpha$-kafirin genes (k1CF: $5^{\prime}$-CAACGTCCTCACAACAATGGC- $3^{\prime}$; k1CR $5^{\prime}$-TCCAACGATGGGTTGCTGCCA-3') was used to amplify all non-truncated kafirins from genomic DNA and endosperm cDNA from P721N and P721Q. PCR products from genomic DNA were cloned into T-easy vector (Promega) and 96 colonies for each sample were picked to sequence on ABI-3730. For cDNA sequencing, RNA was extracted from whole-developing sorghum grains from selfpollinated (18-22 DAP) P721N and P721Q plants, and DNase-treated and cDNAsynthesized according to a previously described method ${ }^{32}$. The $\alpha$-kafirin cDNAs were amplified using the above primers and cloned into pJET (Fermentas). A total of $96 \alpha$-kafarin clones, confirmed with colony PCR, were sequenced from P721N and P721Q with universal pJET primers and aligned using Codon-code Alligner.
Maize transformation. The mutant $22-\mathrm{kDa} \alpha$-kafirin copy was driven by the maize $22-\mathrm{kDa} \alpha$-zein promoter and coupled to the visible GFP marker driven by the maize $18-\mathrm{kDa} \delta$-zein promoter. The two gene cassettes were inserted into the binary vector pTF102 (Fig. 6a). About 200 immature embryos (1.5-2.0 mm), collected around $10 \mathrm{DAP}$ from crosses of Hi-II B and A lines, were dissected for transformation $^{33}$. After two rounds of selection with bialaphos, the fast-growing and friable calli were subjected to regeneration. The positive transformation events could be confirmed by PCR with the primer pair k1CF and k1CR as described above.

RT-PCR. Total RNA was extracted by using TRIzol reagent (Invitrogen). A total of $5 \mu \mathrm{g}$ RNA was digested with DNase I (Invitrogen) and then reverse transcribed. $h d h l$ primer pair has been mentioned above; the Actin and Bip gene primer pairs were Actin-F, 5'-GCCGGTTTCGCTGGTGATGATGCGCC-3'; Actin-R, 5' -GTGA TCTCCTTGCTCATACGATCGGC-3', and Bip-F, $5^{\prime}$-TTGTTCGCGTTTTCAG TTGC-3'; Bip-R, 5' -CACGACGAGCTGTAGATGGTT-3'

Western analysis. Prolamins were extracted according to a previously described method $^{34}$ and separated on 15\% polyacrylamide SDS-PAGE gels, transferred to nitrocellulose and probed with total rabbit $\alpha$-zein antiserum at 1/10,000 dilution. Secondary antibody was horse radish peroxidase-conjugated goat anti-rabbit (Pierce) used at 1/5,000 dilution, and the detection was done with the West Pico chemiluminescent detection system (Pierce).

Transmission electron microscopy. Two-millimetre thick sections were sliced perpendicular to the aleurone layer in order to include the pericarp, aleurone and 10-20 cell layers of the endosperm. All these slices were fixed in 5\% glutaraldehyde in $0.1 \mathrm{M}$ sodium cacodylate buffer, $\mathrm{pH} 7.4$, containing $2 \%$ sucrose in a $2 \mathrm{ml}$ tube. Samples were fixed overnight at $4{ }^{\circ} \mathrm{C}$ and for another $3 \mathrm{~h}$ at room temperature. The tissues were rinsed for $2-3 \mathrm{~h}$ with several changes of $0.1 \mathrm{M}$ sodium cacodylate buffer containing decreasing amounts of sucrose. They were then post-fixed in buffered $1 \%$ Osmium Tetroxide at $4{ }^{\circ} \mathrm{C}$ overnight followed by dehydration in a graded series of acetone and embedded in Epon resin. Ninety-millimetre thin sections were cut on a Leica EM UC6 ultramicrotome using a diamond knife. Sectioned grids were stained with a saturated solution of uranyl acetate and lead citrate. Sections were viewed at $80 \mathrm{Kv}$ with a Philips CM 12 transmission electron microscope.

\section{References}

1. Shelton, M. et al. Grian sorghum by-product feeds for farm animals. Texas Agr. Exp. Sta. Bull. 743, 1-32 (1951).

2. Bressani, R. \& Rios, B. J. The chemical and essential amino acid composition of twenty-five selections of grain sorghum. Cereal Chem. 39, 50-58 (1962).

3. MacLeon, Jr W. C., Lopez de Romana, G., Placko, R. P. \& Graham, G. G. Protein quality and digestibility of sorghum in preschool children: balance studies and plasma free amino acids. J. Nutr. 111, 1928-1936 (1981).

4. Mertz, E. T. et al. Pepsin digestibility of proteins in sorghum and other major cereals. Proc. Natl Acad. Sci. USA 81, 1-2 (1984).

5. Shull, J. M., Watterson, J. J. \& Kirleis, A. W. Proposed nomenclature for the alcohol-soluble proteins (kafirins) of Sorghum bicolor (L. Moench) based on molecular weight, solubility, and structure. J. Agric. Food Chem. 39, 83-87 (1991).

6. Esen, A. A proposed nomenclature for the alcohol-soluble proteins (zeins) of maize (Zea Mays L.). J. Cereal Sci. 5, 117-128 (1987).

7. Shull, J. M., Watterson, J. J. \& Kirleis, A. W. Purification and immunocytochemical localization of kafirins in Sorghum bicolor (L. Moench) endosperm. Protoplasma 171, 64-74 (1992).

8. Lending, C. R. \& Larkins, B. A. Changes in the zein composition of protein bodies during maize endosperm development. Plant Cell 1, 1011-1023 (1989)

9. Hamaker, B. R., Kirleis, A. W., Butler, L. G., Axtell, J. D. \& Mertz, E. T. Improving the in vitro protein digestibility of sorghum with reducing agents. Proc. Natl Acad. Sci. USA 84, 626-628 (1987).

10. Wong, J. H. et al. Digestibility of protein and starch from sorghum (Sorghum bicolor) is linked to biochemical and structural features of grain endosperm. J. Cereal Sci. 49, 73-82 (2009).

11. Duodu, K. G., Taylor, J. R. N., Belton, P. S. \& Hamaker, B. R. Factors affecting sorghum protein digestibility. J. Cereal Sci. 38, 117-131 (2003).

12. Oria, M. P., Hamaker, B. R., Axtell, J. D. \& Huang, C. P. A highly digestible sorghum mutant cultivar exhibits a unique folded structure of endosperm protein bodies. Proc. Natl Acad. Sci. USA 97, 5065-5070 (2000).

13. Weaver, C. A., Hamaker, B. R. \& Axtell, J. D. Discovery of grain plasm with high uncooked and cooked in vitro protein digestibilities. Cereal Chem. 75, 665-670 (1998).

14. Dowling, L. F., Arndt, C. \& Hamaker, B. R. Economic viability of high digestibility sorghum as feed for market broilers. Agron. J. 94, 1050-1058 (2002).

15. Mohan, D. P. Chemically Induced High-Lysine Mutant in Sorghum bicolor (L.) Moench. PhD Thesis (Purdue University, West Lafayette, IN, USA, 1975). 
16. Vasal, S. K., Villegas, E., Bjarnason, M., Gelaw, B. \& Goertz, P. Genetic modifiers and breeding strategies in developing hard endosperm opaque 2 materials. In Improvement of Quality Traits of Maize for Grain and Silage Use . (eds Pollmer, W. G. \& Phipps, R. H.) pp 37-73 (Martinus Nijhoff, London, UK, 1980).

17. Prasanna, B. M., Vasal, S. K., Kassahun, B. \& Singh, N. N. Quality protein maize. Curr. Sci. 81, 1308-1319 (2001).

18. Tesso, T. et al. A novel modified endosperm texture in a mutant high protein digestibility/high-lysine grain sorghum [Sorghum bicolor (L.) Moench]. Cereal Chem. 83, 194-201 (2006).

19. Lending, C. R. \& Larkins, B. A. Effect of the floury-2 locus on protein body formation during maize endosperm development. Protoplasma 171, 123-133 (1992).

20. Coleman, C. E. et al. Expression of a mutant alpha-zein creates the floury2 phenotype in transgenic maize. Proc. Natl Acad. Sci. USA 94, 7094-7097 (1997).

21. Kim, C. S. et al. A defective signal peptide in a $19-\mathrm{kD}$ alpha-zein protein causes the unfolded protein response and an opaque endosperm phenotype in the maize De*-B30 mutant. Plant Physiol. 134, 380-387 (2004).

22. Coleman, C. E., Lopes, M. A., Gillikin, J. W., Boston, R. S. \& Larkins, B. A. A defective signal peptide in the maize high-lysine mutant floury 2. Proc. Natl Acad. Sci. USA 92, 6828-6831 (1995).

23. Gillikin, J. W. et al. A defective signal peptide tethers the floury-2 zein to the endoplasmic reticulum membrane. Plant Physiol. 114, 345-352 (1997).

24. Xu, J. H., Bennetzen, J. L. \& Messing, J. Dynamic gene copy number variation in collinear regions of grass genomes. Mol. Biol. Evol. 29, 861-871 (2012).

25. Oria, M. P., Hamaker, B. R., Axtell, J. D. \& Huang, C. P. A highly digestible sorghum mutant cultivar exhibits a unique folded structure of endosperm protein bodies. Proc. Natl Acad. Sci. USA 97, 5065-5070 (2000).

26. Xu, J. H. \& Messing, J. Organization of the prolamin gene family provides insight into the evolution of the maize genome and gene duplications in grass species. Proc. Natl Acad. Sci. USA 105, 14330-14335 (2008).

27. Song, R., Segal, G. \& Messing, J. Expression of the sorghum 10-member kafirin gene cluster in maize endosperm. Nucleic Acids Res. 32, e189 (2004).

28. Gardner, J. C., Maranville, J. W. \& Paparozzi, E. T. Nitrogen use efficiency among diverse sorghum cultivars. Crop Sci. 34, 728-733 (1994).

29. Wu, Y., Holding, D. R. \& Messing, J. Gamma-zeins are essential for endosperm modification in quality protein maize. Proc. Natl Acad. Sci. USA 107, 12810-12815 (2010).
30. Wu, Y. \& Messing, J. Novel genetic selection system for quantitative trait loci of quality protein maize. Genetics 188, 1019-1022 (2011).

31. Wu, Y. \& Messing, J. RNA interference can rebalance the nitrogen sink of maize seeds without losing hard endosperm. PLoS One 7, e32850 (2012).

32. Holding, D. R. et al. Characterization of opaque 2 modifier QTLs and candidate genes in recombinant inbred lines derived from the K0326Y quality protein maize inbred. Theor. Appl. Genet. 122, 783-794 (2011).

33. Wu, Y. \& Messing, J. Rapid divergence of prolamin gene promoters of maize after gene amplification and dispersal. Genetics 192, 507-519 (2012).

34. Wallace, J. C., Lopes, M. A., Paiva, E. \& Larkins, B. A. New methods for extraction and quantitation of zeins reveal a high content of gamma-zein in modified ppaque-2 maize. Plant Physiol. 92, 191-196 (1990).

\section{Acknowledgements}

The research described in this manuscript was supported with the Selman A. Waksman Chair in Molecular Genetics to Y.W. and J.M. Work done by L.Y., X.G. and D.R.H. was supported by the Department of Agronomy and Horticulture and the Center for Plant Science Innovation, University of Nebraska, Lincoln (UNL). We thank Dr. Gebisa Ejeta and Dr. Bruce Hamaker for providing the hdhl mutant (P721Q) and its wild-type (P721N) isolines; and Drs Brian Larkins and Brenda Hunter for providing the $\alpha$-zein antiserum.

\section{Author contributions}

Y.W. designed and performed experiments. Y.W. drafted the manuscript. D.R.H., L.Y. and X.G. performed experiments. D.R.H. and J.M. designed experiments and wrote the manuscript.

\section{Additional information}

Accession code: The sequence of mutant kafirin has been deposited in Genbank under accession code KF141792.

Competing financial interests: The authors declare no competing financial interests.

Reprints and permission information is available online at http://npg.nature.com/ reprintsandpermissions/

How to cite this article: $\mathrm{Wu}, \mathrm{Y}$. et al. Mutation in the seed storage protein kafirin creates a high-value food trait in sorghum. Nat. Commun. 4:2217 doi: 10.1038/ncomms3217 (2013). 